\title{
A ascensão chinesa na nova era sob a perspectiva do realismo ofensivo: rumo a uma nova hegemonia?
}

The rise of China under the perspective of offensive realism: towards a new hegemony?

\section{Leonardo Carvalho Leite Azeredo Bandarra1}

\section{Resumo}

A ascensão da China é tema patente das relações internacionais contemporâneas, portanto analisada, exaustivamente, por diversos especialistas em política internacional. Considerando o atual estado da arte da teoria das relações internacionais, o presente artigo busca aplicar ao caso chinês o quadro teórico desenvolvido pela corrente de pensamento denominada "realismo ofensivo", a qual ainda detém grande influência em meio às teorias hegemônicas das Relações Internacionais. Por meio de aplicação do quadro analítico de teóricos como John Mearsheimer, conclui-se aqui que a China atua, primordialmente, como potência regional no subsistema asiático, não global.

Palavras-chave: realismo ofensivo; teoria das relações internacionais; ascensão da China

\begin{abstract}
The rise of China is an ever-present issue patent of contemporary international relations, therefore extensively analyzed by sundry experts of international politics. Considering the current state of the art concerning International Relations Theory, this article seeks to apply to the case of China the theoretical framework developed by the school of thought called "offensive realism", which still holds great influence among the theoretical mainstream of International Relations. Through the application of the analytical framework developed by theorists such as John Mearsheimer, it is hereby concluded that China primarily acts as a regional power in the Asian sub-system, not as a global one.
\end{abstract}

Keywords: offensive realism; theory of International Relations; China's Rise

\footnotetext{
${ }^{1}$ Mestrando em Relações Internacionais pela Universidade de Brasília, com concentração em História das Relações Internacionais. Bolsista da Coordenação de Aperfeiçoamento de Pessoal de Nível Superior (CAPES) (1clab90@gmail.com), Brasília, Brasil.
} 


\section{Introdução}

Detentora de uma pujante economia que, desde as reformas de mercado iniciadas em 1978 apresenta notável taxa de crescimento médio anual do Produto Interno Bruto (PIB) de 10\%, além de abrigar a maior população do mundo, com 1,3 bilhão de habitantes², em 2013, a República Popular da China apresenta-se como um novo e relevante ator internacional, cuja ascensão levanta uma série de suposições acerca da sua possível transformação em uma nova potência hegemônica global.

Tendo em vista a relevância que apresenta esse país na atual configuração internacional, o presente ensaio objetiva analisar a presença chinesa no cenário mundial contemporâneo, discutindo, entrementes, a atual configuração do sistema internacional - ou seja, se este é, de fato, multipolar. De forma mais específica, trata-se de um estudo de caso que buscará responder a seguinte pergunta: Seria a China uma potência pretensiosamente hegemônica em âmbito mundial? .

Nesse sentido, com vistas a melhor atender ao designo supracitado, dividir-se-á este ensaio em três partes, além da presente introdução. A primeira parte busca realizar uma breve discussão acerca do conceito de "hegemonia", a partir de uma perspectiva realista ofensiva, como desenvolvido pelo teórico realista-ofensivo John Mearsheimer. A segunda parte, por sua vez, buscará aplicar o exposto na parte anterior à atual movimentação internacional chinesa no contexto internacional, com vistas a analisar se, de fato, se observa a uma pretensão chinesa à hegemonia internacional. A última parte consta de uma concisa conclusão quanto ao tema.

\section{0 conceito de hegemonia em uma abordagem realista ofensiva}

A configuração do atual sistema internacional é objeto de diversos debates e de falta de consenso entre os teóricos das relações internacionais. Com o imprevisto e derradeiro fim da Guerra Fria e da estrutura bipolar, aquela que Kenneth Waltz (1979) afirmou ser a mais estável dentre as diversas possibilidades existentes nas

2 Segundo dados do Banco Mundial. Disponíveis em:

<http://www.worldbank.org/en/country/china/overview>, acessado em 07/05/2013.

Conjuntura Global, vol. 4 n.3, set./dez., 2015, p. 305-317. 
relações interestatais e que muitos estudiosos da vertente neorrealista acreditavam terminaria em confronto bélico entre as duas superpotências, seguiuse, então, uma nova configuração internacional, marcada pela consolidação da primordialidade de novas temáticas, como a energética e ambiental, e uma nova ordem, a qual alguns especialistas acreditam ser multipolar, enquanto outros afirmam ser unipolar, com a predominância americana.

Retomou-se a discussão corrente desde o final da década de 1970 acerca dos benefícios da criação de instituições, e teóricos institucionalistas neoliberais retomaram o otimismo quanto à eficiência das instituições como restrições à atuação estatal, como afirmou John Kenberry (2001). Isso ocorreria porque as instituições manteriam a estabilidade da ordem internacional, mesmo ante o fim da Guerra Fria e um possível enfraquecimento da grande superpotência americana, dado que os Estados estariam encapsulados (locked in) pelas normas e regras criadas já após a Segunda Guerra Mundial.

Concomitantemente à revitalização da teoria neoliberal, reemergiu uma também revigorada vertente neorrealista, que recuperava a análise do sistema internacional enquanto um ambiente guiado basicamente pelo conceito de equilíbrio de poder. Tal vertente é melhor exemplificada por John Mearsheimer (2007), que, embora reconheça a importância das instituições internacionais, enfoca-se na ideia de que os Estados se movem internacionalmente de forma egoísta, desconfiada, e movidos pelo medo, pela busca da sobrevivência e em um ambiente anárquico no qual o que lhe resta é a autoajuda (self-help).

Dessa forma, continua Mearsheimer (2007), todo Estado, não importando quão fraco seja, deteria poder ofensivo, de forma a ser de capaz de, pelo menos, causar danos a outro Estado desafiante. Uma potência hegemônica, nesta linha de raciocínio, seria aquela que possuísse maior quantidade de recursos de poder que as demais, sendo, portanto, capaz de destruir qualquer outra que a ela desafie. A hegemonia seria, ademais, influenciada pelas próprias características do sistema internacional anárquico, que "encoraja os Estados a buscarem(-na)" (MEARSHEIMER, 2007, p. 29).

Como se deve medir esses recursos de poder necessários para que determinado Estado se torne uma potência hegemônica? Em uma visão realista ofensiva, deve-se analisar a "capacidade militar relativa" das potências em relação 
às demais (MEARSHEIMER, 2007, p. 23), o que definiria, em última instância, o seu poder. Para Mearsheimer (2007), o poder de uma potência seria formado por dois componentes: (1) o chamado poder militar - que seria, de fato, a capacidade ofensiva disponível por um Estado, por exemplo, seu efetivo nas forças armadas -, e (2) o poder latente - que seriam os recursos passíveis de serem transformados em poder militar, composto basicamente "da riqueza de um Estado e na dimensão total da sua população" (MEARSHEIMER, 2007, p. 67).

Cabe fazer, entretanto, duas ressalvas quanto a tais recursos de poder. Primeiramente, deve-se destacar o papel central da tecnologia no processo de melhoria da capacidade militar de determinada potência, o que será obtido a partir da riqueza que detém o Estado (um dos elementos do poder latente). A segunda ressalva é quanto à inviabilidade da existência de um poder hegemônico global, justificável por duas razões. Em primeiro lugar, devido à impossibilidade de "uma superioridade nuclear inequívoca", dada a característica destrutiva marcante que possui cada arma nuclear, o que torna o ganho relativo contraído pela obtenção de uma maior quantidade de armas desse tipo algo pouco significativo. Isso ocorre porque o poder que possui um Estado detentor de apenas uma dessas armas já é suficientemente enorme, apesar de esse poder ser minorado ou majorado por meio de elementos complementares, como a tecnologia de entrega (delivery) e a capacidade de segunda onda de ataques (second strike capabiliy) - ambos elementos não considerados por Mearsheimer. A segunda razão é o poder limitador de grandes massas de água, visto que existe uma dificuldade de "projetar o poder através dos oceanos do mundo até ao território de uma grande rival” (MEARSHEIMER, 2007, p. 54). Dessa forma, restaria aos Estados, tão somente, a busca pela hegemonia regional, dadas as ditas limitações inerentes à sua capacidade de projeção de poder.

Ainda no referente ao enquadramento teórico de Mearsheimer, cabe salientar as características da configuração do sistema internacional, ou seja, a forma como ele organiza. Como, segundo essa vertente teórica, a existência de uma potência hegemônica global é algo não viável no mundo atual, descarta-se, portanto, a ideia de um sistema unipolar, restando, logo, duas possibilidades remanescentes: a bipolaridade e a multipolaridade. Ambas configurações restantes podem ser tanto equilibradas - quando se tem duas ou mais potências concorrentes com poderes 
similares - quanto desequilibradas - quando existe uma grande disparidade de poder entre as potências.

Qual seria, segundo o quadro analítico delimitado, a configuração atual? Para Mearsheimer (2007) existem vários cenários concomitantes no mundo atual, ganhando destaque, para os fins deste ensaio, o cenário asiático, onde se observa a um equilíbrio entre China, Rússia e Estados Unidos, porém com a séria possibilidade de desequilíbrio futuro a médio e longo prazo, resultado de uma ascensão chinesa, a qual desequilibraria o subsistema em favor do país do meio e a qual levaria a subsistema multipolar desequilibrado, que faz parte de um sistema internacional multipolar mais amplo.

Delineado o quadro teórico a ser utilizado, parte-se para uma análise específica acerca da realidade chinesa, a partir de um questionamento quanto à sua movimentação internacional atual.

\section{A movimentação internacional chinesa em uma configuração multipolar}

Seria a China uma potência que busca a hegemonia? Que tipo de potência visaria se tornar a China? Segundo a visão realista ofensiva delineada na seção anterior, a China busca, em última instância, tornar-se uma potência hegemônica, na medida em que, não obstante a retórica oficial do governo chinês, esse é o objetivo de todos os Estados, movidos pelo medo e com vistas a sobreviver em um ambiente internacional anárquico. Seria esse panorama realista aplicável ao caso chinês? Em caso positivo, como se observa tal constatação em meio à atuação internacional chinesa?

Como observam Randall Schweller e Xiaoyu Pu (2011), os próprios estrategistas chineses levam em consideração em seu cálculo estratégico a força relativamente inferior chinesa, se comparada com a dos Estados Unidos. Contudo, isso não significa que o país não atue de forma revisionista para um período de tempo imediato, visto que também inerente à estratégia chinesa é uma visão de longo prazo das transformações do sistema internacional. Dessa forma, os chineses buscariam utilizar as instituições internacionais como forma de alcançar uma agenda de reforma gradualista, além de utilizar, cada vez mais, o seu poder financeiro e estratégias da diplomacia do soft power como forma de adquirir 
influência política e diplomática, contrabalanceando, assim, a hegemonia americana.

Deste modo, continuam Schweller e Pu (2011), a atuação internacional chinesa poderia ser chamada de low profile, com ressalvas para questões que envolveriam sua integridade territorial, como a de Taiwan, do Tibet, do Mar do Sul da China. Essa estratégia não excluiria, contudo, o caráter primordial do poder militar no referido cálculo. De fato, como lembram Schweller e $\mathrm{Pu}$ (2011), em última instância, as grandes potências regionais na Ásia, que seriam a China e os Estados Unidos, poderiam recorrer à força, como forma de criar uma nova ordem estratégia esta que não seria viável, inclusive, pois, como lembra Li (2011), a China tem sido a "maior beneficiária do sistema existente durante as últimas três décadas" (LI, 2011, p. 346, tradução livre) e, ademais, cabe lembrar que as grandes potências trabalham arduamente para "desencorajar guerras nas quais venham a ser as vítimas prováveis" (MEARSHEIMER, 2007, p. 61), como poderia ser a China em caso de confronto com os Estados Unidos.

Assim, acredita-se, a priori, que a China não seria, em curto prazo, uma potência revisionista, mas que buscaria instaurar, em longo prazo, uma nova ordem internacional, bem como alcançar o status de potência hegemônica. Seria tal visão compatível com a visão especifica chinesa no que concerne ao funcionamento das relações internacionais?

\section{A Visão de Mundo Chinesa e os desafios histórico e militar}

Historicamente, a China é um país cujos líderes aprenderam a entender sua condição única, marcada pela persistente propensão à desordem doméstica, causada por ameaças externas (JISI, 2011). Assim, logo após a ascensão de Mao Zedong ao poder, o país buscou aplicar o conceito de "interesse nacional" para delinear seus objetivos estratégicos, o que, na época, implicou na predominância dos interesses de segurança militar e política, baseando-se para tal em um pensamento de tradição leninista, segundo o qual o mundo era dividido entre arqui-inimigos, inimigos secundários, aliados em potencial e forças revolucionárias. 
Já na década de 1980, sob Deng Xiaoping, a China elevou o desenvolvimento econômico ao topo das suas prioridades, desenvolvendo uma política externa que, em larga medida, distanciava-se da de Mao, visando a desenvolver relações cooperativas e amigáveis com diversos países ao redor do globo, buscando assim manter um ambiente internacional pacífico (JISI, 2011).

Recentemente, sob o ex-presidente Hu Jintao, o país formulou uma nova agenda para o desenvolvimento, promovendo o rápido crescimento econômico e enfatizando a "boa governança, aprimorando a rede de seguros sociais, protegendo o meio-ambiente, encorajando a inovação independente, reduzindo as tensões sociais, aperfeiçoando o sistema financeiro e estimulando o consumo doméstico" (JISI, 2011, p. 67, tradução livre).

Não obstante a descrita mudança de enfoque que sofreu a estratégia internacional chinesa nos anos recentes, deve-se destacar que, para os líderes chineses a nível discursal, o país ainda se move segundo uma visão de mundo tradicional e única, que se diferencia consideravelmente da do Ocidente. Assim, enquanto que o sistema de origem europeia desenvolveu um ordenamento do sistema internacional envolto pela anarquia e gerido por Estados-nação "westfalianos", o discurso tradicional Chinês baseia-se no princípio do Tianxia (tudo abaixo do céu), que induz à construção de uma "forma altruísta de unidade global”, apoiada por uma "'hierarquia global', na qual a ordem é mais valiosa que a liberdade, a ética que a lei e a governança elitista que a democracia e os direitos humanos" (LI, 2011, 145).

Embora autores, como o próprio Li (2011), além do Schweller e do Pu (2011) afirmem ser este um empreendimento utópico, a própria realidade internacional exposta pelo realismo ofensivo é capaz de se relacionar com esta visão única de mundo, em especial no que tange à noção da busca pela descrita "hierarquia", o que implicaria, paralelamente, na busca pela hegemonia - ou seja, por uma ordem na qual a China se posicione em uma posição privilegiada face aos demais Estados. Seria, sob outra perspectiva, a própria hegemonia uma etapa prévia para a construção de uma ordem sob o Tianxia? Tal questão não é de fácil resposta e merece futuros estudos. Acredita-se, porém, na pretensão chinesa de busca pela hegemonia, o que induziria o temor dos Estados Unidos em ser expulso da Ásia por meio da formação de um bloco regional que o excluísse, formado pela China, 
motivada pelo grande medo estratégico que possui das melhorias militares nos países de sua periferia, o que poderia levar à existência de atores capazes de se intrometer em suas instituições domésticas e de ameaçar o seu território (KISSINGER, 2012). Assim, ter-se-ia um cenário regional, no qual duas grandes potências, movidas pelo medo resultante da leitura feita das aspirações de sua rival, desenvolveriam politicas de contensão a outra, com vistas a manter ou alcançar a hegemonia.

Não obstante a incipiente retórica chinesa na área da segurança, excetuando-se a questão de Taiwan, cuja anexação pela China Continental ainda é um entrave para as relações sino-americanas (GLASER, 2011), a China vem se desenvolvendo progressivamente no setor militar, principalmente no que tange ao incremento de sua tecnologia aérea e espacial, além da modernização de seu exército e de sua frota naval. Ademais, o "reino do meio" também estabeleceu um corolário, segundo o qual buscaria, formar alianças estratégicas com os países vistos como desafiantes ao Ocidente, como o Irã, a Coreia do Norte e a Rússia, além de comprar e usar os títulos do tesouro americano como um instrumento político, estando pronta para vendê-los em caso de ameaça americana (JISI, 2011).

Por outro lado, conforme afirma Henry Kissinger (2012), a política americana para a Ásia tem se baseado em uma tentativa de evitar uma guerra nuclear e, de forma mais recente, em considerações ficais e orçamentárias, que limitam a sua capacidade de ação. Além disso, vale salientar a própria característica da mobilização internacional chinesa, que tem buscado crescentemente por arranjos econômicos alternativos aos Estados Unidos, como os canais de câmbios separados estabelecidos com o Brasil e o Japão. Enquanto isso, os Estados Unidos tentam incorporar a China em uma estrutura econômica específica, convidando-a participar, por exemplo, o Acordo Estratégico Trans-Pacífica de Cooperação Econômica (TPP) - um acordo de livre comércio ligando a Ásia à América (KISSINGER, 2012). Em meio a tal desenho específico feito pelos americanos e aos protestos americanos para que a China modifique a sua economia orientada à exportação e movida pelo consumo, surge, continua Kissinger (2012), a dúvida se as relações sino-americanas rumariam à cooperação ou, simplesmente seguiriam os padrões históricos de rivalidade. 
O Tanxia, seria, assim, para a visão aqui exposta, uma tentativa de revisão da ordem internacional colocando a China no centro, mas ainda se coadunaria com os princípios definidores do sistema internacional e pelos condicionantes que movem os Estados westfalianos. Entre esses condicionantes, destacar-se-iam elementos intrínsecos às capacidades materiais dos Estados, como fatores econômicos e militares.

\section{A Questão Econômica e o Multilateralismo}

Outra faceta importante, e inclusive a, normalmente, mais documentada da movimentação internacional chinesa, é o desenvolvimento econômico. Atualmente, a China se mostra como a segunda maior economia do globo, em questão de PIB, de modo que muitos estudiosos destacam a pujança econômica chinesa como principal face do seu interesse nas relações internacionais. Nesse sentido, destacase outra relevante característica da nova estratégia chinesa, qual seja o primado por uma atuação multilateral (JISI, 2011).

O multilateralismo é para a China uma forma de manter a estabilidade do sistema internacional, o que seria, tal qual afirma Mearsheimer (2007), desejável a todos, visto que a paz reduz os custos para a manutenção da ordem pelas potências hegemônicas. Ademais, a China tem tido uma crescente presença em fóruns multilaterais econômicos, como o G20 financeiro e os BRICS, e mesmo na formação de alianças multilaterais para a segurança internacional, tendo como base retórica a ênfase na construção de uma ordem internacional harmônica e centrada no conceito de he (paz, harmonia) (LI, 2011). Assim, a política chinesa buscaria diminuir a imagem da "ameaça chinesa" enquanto constrói uma de "poder responsável”, reduzindo assim as apreensões acerca de sua ascensão (LI, 2011).

Apesar de parecerem pouco condizentes com o framework do realismo, a política de inserção econômica chinesa no sistema internacional pauta-se pela busca de alianças e de maior capacidade de poder. Nessa política, sobressai-se a presença chinesa no chamado G20 financeiro, que é, segundo Li (2011), a principal arena para os chineses, visto o seu caráter ad hoc, o seu objetivo de discutir questões de governança global, com vistas a estabelecer um mecanismo eficiente de controle financeiro, e o seu caráter garante, mas que busca por um equilíbrio 
entre a representação e a eficiência - pois, embora possua uma quantidade de membros menos restrita que o G8 dos países desenvolvidos, não é tão abrangente a ponto de interferir em sua eficiência, como o são as Nações Unidas.

A flexibilidade dos mecanismos ad hoc permite à China maior margem para ampliar seus mecanismos de poder, sem criar mecanismos que minem os interesses próprios chineses. Isso pode ser exemplificado pelo próprio G20, o qual expressaria a presença chinesa em meio a elite de nações que buscariam regular o sistema financeiro internacional, com vistas a torná-lo mais estável e coerente com sua busca de obter maior capacidade material de poder, sem, contudo, abrir demasiadamente as opções da ordem, de modo a criar disparidades de poder inerentes ao sistema internacional (PAYNE, 2010). A participação em arenas como o G20 pode ser vista como uma maneira de manter a pujança do país, o que também seria de suma relevância para a ampliação do poder internacional chinês, visto ser a riqueza um dos principais componentes do poder latente. Inclusive, como destaca Subramanian (2011), projeta-se que, embora sofra uma redução de seu crescimento, a China tornar-se-á a maior potência econômica global, suplantando os Estados Unidos em 2030, o que implicará em uma ampliação da importância do Yuan enquanto câmbio concorrente ao Dólar americano.

Destaca Subramanian (2011) que, apesar do vigor econômico, ainda restariam importantes desafios sociais a serem considerados pela China antes de alcançar a hegemonia, dentre os quais se incluiriam a busca de alcançar maiores índices de qualidade de vida e maior estabilidade social. Caso esses desafios não sejam vencidos, gerar-se-ão implicações, até mesmo, para o setor militar, visto que países pobres possuem dificuldades em taxar suas populações com o objetivo de aumentar a parcela de seu orçamento dedicada a tal setor, que, ademais, não deve ser confiado apenas e em longo prazo à estratégia de financiamento sustentada por orçamentos advindos do exterior (i.e. por exportações).

Não obstante a permanência de certos elementos que reduzem a capacidade latente chinesa, como aqueles relacionados à estabilidade social, a China tem-se movido no sistema internacional de modo a obter posição mais propícia a seus interesses. 0 crescimento econômico chinês - desde as reformas econômicas de Deng Xiaoping - e a conformação de alianças no campo econômico, bem como a maior altivez no setor militar, principalmente a partir da maior presença no mar 
do sul da China e de maior confrontação com o Japão (aliado preferencial dos Estados Unidos no Pacífico), são aspectos claros de como a China tem, nos últimos anos, em especial no governo de Xi Jinping, buscado ampliar sua presença no subsistema asiático.

\section{Considerações Finais}

Seria a China uma potência pretensiosamente hegemônica em âmbito global? Segundo a visão teórica aqui proposta, representa a China de fato um Estado que busca, conscientemente, tornar-se potência hegemônica regional, dada a impossibilidade de existência de uma potência verdadeiramente global, pelas razões delineadas neste texto. Ademais, em um cenário no qual os Estados-nação, movidos pelo medo, primam por sua sobrevivência, apenas assegurada quando estes são hegemônicos, ou seja, possuem maiores recursos de poder relativamente a seus pares, seria pouco provável que a China assume-se uma postura diferente.

Essa ambição seria também impregnada por uma retórica de conformação de uma nova ordem internacional, baseada na hierarquia e na busca de sistema internacional que seguisse os padrões geridos pelo princípio do Tianxia, ou seja, em um sistema hierárquico, com a China em uma posição privilegiada. Essa retórica abarca, ademais, uma estratégia de ascensão pacífica, segundo a qual a China buscar elevar-se na hierarquia internacional de potências, sem despertar, contudo, o temor dos demais países. Segundo vertente realista das Relações Internacionais, essa perspectiva chinesa seria, nada mais, do que uma forma de justificar a busca de posição mais vantajosa no sistema internacional e de modificação da ordem mundial segundo os objetivos chineses de obtenção de maior espaço no em meio à comunidade internacional.

A própria economia pode ser encarada, dessa forma, como maneira de incrementar os seus recursos de poder, na medida em que gera riqueza - um dos elementos principais que compõem o poder latente, que é parte do poder ofensivo de um Estado. Nesse sentido, a China busca manter um sistema econômico e financeiro estáveis, a partir da formação de alianças e da proatividade em organismos multilaterais, como o G20, com vistas a estabelecer uma ordem a ela benéfica e que permita a manutenção de seu grande crescimento econômico. Ainda 
na esfera econômica, inclui-se a estratégia chinesa de adquirir real capacidade de influência sob os Estados Unidos, mantendo-se para isso como a principal detentora de títulos do tesouro americano.

No campo da segurança, que ganha grande relevância em uma análise realista das relações internacionais, destacam-se na estratégia chinesa uma busca pela renovação de exército e armamentos, além de investimentos no setor aeroespacial. Embora seja esse um campo no qual a China tem mantido uma atuação de baixo perfil, vale salientar a ênfase que se tem dado às questões que dizem respeito à sua integridade territorial, em especial no tangente ao reconhecimento de Taiwan como Estado - a principal razão pela qual declaradamente entraria em confronto com outro Estado. Também nesse ponto nota-se a existência de uma política de alianças estratégicas com Estados que mantêm postura crítica com relação ao Ocidente, tal como Coreia do Norte, Irã e Rússia, o que poderia evidenciar uma tentativa de contraposição ao seu principal adversário à hegemonia, os Estados Unidos.

As próprias relações sino-americanas são marcadas por um caráter duplo, a saber: se por um lado realizam os países políticas cooperativas, como exemplificado pelo pedido americano para que a China se junte à iniciativa do TPP, por outro lado também são relações baseadas no medo mútuo - do lado chinês, a potencial ajuda americana para o enfraquecimento de sua periferia, pondo em risco a sua integridade territorial e as suas instituições domésticas, e, do lado americano, a perda da sua posição hegemônica tanto no continente quanto em questões econômicas, como visto pelas críticas americanas ao modelo econômico chinês.

Dessa maneira, como visto, representa a China, tanto na esfera de segurança, quanto na econômica e política, o objetivo de se tornar uma potência hegemônica, o que garantiria a sua sobrevivência inabalável no sistema internacional. Entrementes, buscaria a China manter a estabilidade do sistema em uma ordem multipolar, o que seria desejável tanto por ela, quanto pelas potências a ela concorrentes, como os Estados Unidos. 


\section{Referências}

WALTZ, Kenneth. "Theory of International Politics". Long Grove: Waveland Press, 1979. 1st Edition.

IKENBERRY, John. “After Victory”. Princeton: Princeton University Press, 2001.

MEARSHEIMER, John. "A Tragédia da Política das Grandes Potências". Lisboa: Gradiva, 2007.

JISI, Wang. "China's search for a grand strategy: a rising great power finds its way". In Foreign Affairs 90.2 (March-April 2011): pg 68-73.

SUBRAMANIAN, Arvind. "Why China's dominance is a sure thing" In Foreign Affairs 90.5 (September-October 2011).

GLASSER, Charles. "Will China's rise lead to war? Why Realism does not mean pessimism". In Foreign Affairs 90.2 (March-April 2011): pg 80-85.

LI, Mingjiang. "Rising from within: China's search for Multilateral World and its implications for Sino-Soviet Relations". In Global Governance 17 (2011), pg 331351.

KISSINGER, Henry. "The future of U.S.-Chinese relations: conflict is a choice, not a necessity". In Foreign Affairs, 91.2 (March-April 2012): pg 44-49.

PAYNE, Anthony. "How many Gs are there in 'global governance' after the crisis? The perspectives of the 'margina majority' of the world's states". In International Affairs 86: 3 (2010), pg 729-740.

SCHWELLER, Randall L.; PU, Xiaoyu. "After Unipolarity. China's Vision of International Order in na Era of U.S. Decline." Im International Security, 36: 1 (2011), pg. 41-72. 